\title{
Plasma, oral fluid and sweat wipe ecstasy concentrations in controlled and real life conditions.
}

Citation for published version (APA):

Samyn, N., de Boeck, G., Wood, M. M., Lamers, C. T. J., Waard, D. D., Brookhuis, K. A., Verstraete, A. G., \& Riedel, W. J. (2002). Plasma, oral fluid and sweat wipe ecstasy concentrations in controlled and real life conditions. Forensic Science International, 128(12), 90-97. https://doi.org/10.1016/S03790738(02)00157-3

Document status and date:

Published: 01/01/2002

DOI:

10.1016/S0379-0738(02)00157-3

Document Version:

Publisher's PDF, also known as Version of record

Document license:

Taverne

Please check the document version of this publication:

- A submitted manuscript is the version of the article upon submission and before peer-review. There can be important differences between the submitted version and the official published version of record.

People interested in the research are advised to contact the author for the final version of the publication, or visit the DOI to the publisher's website.

- The final author version and the galley proof are versions of the publication after peer review.

- The final published version features the final layout of the paper including the volume, issue and page numbers.

Link to publication

\footnotetext{
General rights rights.

- You may freely distribute the URL identifying the publication in the public portal. please follow below link for the End User Agreement:

www.umlib.nl/taverne-license

Take down policy

If you believe that this document breaches copyright please contact us at:

repository@maastrichtuniversity.nl

providing details and we will investigate your claim.
}

Copyright and moral rights for the publications made accessible in the public portal are retained by the authors and/or other copyright owners and it is a condition of accessing publications that users recognise and abide by the legal requirements associated with these

- Users may download and print one copy of any publication from the public portal for the purpose of private study or research.

- You may not further distribute the material or use it for any profit-making activity or commercial gain

If the publication is distributed under the terms of Article $25 \mathrm{fa}$ of the Dutch Copyright Act, indicated by the "Taverne" license above, 


\title{
Plasma, oral fluid and sweat wipe ecstasy concentrations in controlled and real life conditions
}

\author{
Nele Samyn ${ }^{\mathrm{a}, *}$, Gert De Boeck ${ }^{\mathrm{a}}$, Michelle Wood ${ }^{\mathrm{b}}$, Caroline T.J. Lamers ${ }^{\mathrm{c}}$, \\ Dick De Waard $^{\mathrm{d}}$, Karel A. Brookhuis ${ }^{\mathrm{d}}$, Alain G. Verstraete ${ }^{\mathrm{e}}$, Wim J. Riedel ${ }^{\mathrm{c}}$ \\ ${ }^{a}$ Drugs and Toxicology, Section Toxicology, National Institute of Criminalistics and Criminology, \\ Vilvoordsesteenweg 100, 1120 Brussels, Belgium \\ ${ }^{\mathrm{b}}$ Micromass Ltd., Manchester, UK \\ ${ }^{\mathrm{c}}$ Experimental Psychopharmacology Unit, Brain and Behaviour Institute, Maastricht University, Maastricht, The Netherlands \\ ${ }^{\mathrm{d}}$ Department of Psychology, University of Groningen, Groningen, The Netherlands \\ ${ }^{\mathrm{e}}$ Laboratory of Clinical Biology-Toxicology, Ghent University Hospital, Ghent, Belgium
}

\begin{abstract}
In a double-blind placebo controlled study on psychomotor skills important for car driving (Study 1), a $75 \mathrm{mg}$ dose of $\pm 3,4-$ methylenedioxymethamphetamine (MDMA) was administered orally to 12 healthy volunteers who were known to be recreational MDMA-users. Toxicokinetic data were gathered by analysis of blood, urine, oral fluid and sweat wipes collected during the first $5 \mathrm{~h}$ after administration. Resultant plasma concentrations varied from 21 to $295 \mathrm{ng} / \mathrm{ml}$, with an average peak concentration of $178 \mathrm{ng} / \mathrm{ml}$ observed between 2 and $4 \mathrm{~h}$ after administration. MDA concentrations never exceeded $20 \mathrm{ng} / \mathrm{ml}$. Corresponding MDMA concentrations in oral fluid, as measured with a specific LC-MS/MS method (which required only $50 \mu 1$ of oral fluid), generally exceeded those in plasma and peaked at an average concentration of $1215 \mathrm{ng} / \mathrm{ml}$. A substantial intra- and inter-subject variability was observed with this matrix, and values ranged from 50 to $6982 \mathrm{ng} / \mathrm{ml}$ MDMA. Somewhat surprisingly, even 4-5 h after ingestion, the MDMA levels in sweat only averaged $25 \mathrm{ng} /$ wipe.

In addition to this controlled study, data were collected from 19 MDMA-users who participated in a driving simulator study (Study 2), comparing sober non-drug conditions with MDMA-only and multiple drug use conditions. In this particular study, urine samples were used for general drug screening and oral fluid was collected as an alternative to blood sampling. Analysis of oral fluid samples by LC-MS/MS revealed an average MDMA/MDEA concentration of $1121 \mathrm{ng} / \mathrm{ml}$ in the MDMA-only condition, with large inter-subject variability. This was also the case in the multiple drug condition, where generally, significantly higher concentrations of MDMA, MDEA and/or amphetamine were detected in the oral fluid samples. Urine screening revealed the presence of combinations such as MDMA, MDEA, amph, cannabis, cocaine, LSD and psilocine in the multiple-drug condition. (C) 2002 Elsevier Science Ireland Ltd. All rights reserved.
\end{abstract}

Keywords: MDMA; Controlled study; Oral fluid; Sweat; Driving under the influence; LC-MS/MS

\section{Introduction}

The widespread use of ecstasy ( \pm 3 ,4-methylenedioxymethamphetamine; MDMA) by young people in most western countries has caused concern due to its associated accident risks [1]. In a recent roadside study in Belgium, blood

\footnotetext{
* Corresponding author. Tel.: +32-2-240-05-00; fax: 32-2-241-61-05.

E-mail addresses: nele.samyn@just.fgov.be, nele.samyn@kbcmail.net (N. Samyn).
}

analysis of drivers suspected of impairment by the police revealed the presence of MDMA in 35\% of the cases. Multiple drug use was also quite common, with MDMA often associated with amphetamine, cocaine or cannabis [2].

The present paper reports on the toxicological data obtained from two separate studies [3-5] investigating the effects of MDMA alone and the effects of multiple drug use, i.e. MDMA and a variety of other compounds, on driving behaviour. Since pharmacokinetic data on MDMA are scarce, especially for alternative specimens, the purpose of this paper is to compare biological indices of MDMA-use from different 
body fluids, i.e. plasma, oral fluid, sweat and urine and to assess their applicability for future use in actual traffic surveillance (e.g. application of suitable cut-off values) and in forensic accident analysis. In Study 1, 12 experienced MDMA-users were administered MDMA $75 \mathrm{mg}$. Oral fluid and sweat concentrations of MDMA were monitored during the first $5 \mathrm{~h}$ after administration and compared to the corresponding blood and urine concentrations. In Study 2, 19 subjects were instructed to use only one tablet of MDMA before going to a party; they were unrestricted during the party and used anything they liked. Urine and oral fluid samples were collected when subjects visited the institute of the department of psychology in Groningen where they performed a driving simulator test before and after they went out and on a control night when no drugs were allowed.

\section{Experimental design}

\subsection{Study 1}

Twelve experienced MDMA-using but otherwise healthy volunteers (eight male/four female, aged 21-30) were administered MDMA 75 mg (Lipomed, Arlesheim, Switzerland), alcohol $0.5 \mathrm{~g} / \mathrm{kg}$ or placebo according to double-blind, crossover design on three separate occasions, spaced 2 weeks apart. MDMA was dissolved in $25 \mathrm{ml}$ of bitter orange syrup, which was ingested at once. The study was approved by the Hospital Ethics Committee of the University of Maastricht. Before participation written informed consent was obtained. Drug use was restricted 2 weeks prior to and alcohol 1 day prior to the experimental sessions. A Lion SD-3 BreathAlcohol Analyser test and an on-site screening test for the detection of drugs of abuse in urine (Syva Rapidtest, Dade Behring) were performed before the start of the experiment.

An in-dwelling venous catheter was placed in a forearm vein from which blood was drawn at 60 min intervals. Blood samples were taken using Vacutainer ${ }^{\circledR}$ tubes with sodium fluoride and potassium oxalate as anticoagulant (BectonDickinson Benelux, Belgium) from time 0 to $5 \mathrm{~h}$ after administration. Blood samples were cooled to $+4{ }^{\circ} \mathrm{C}$ and centrifuged after each experiment. Following centrifugation, samples were stored at $-20{ }^{\circ} \mathrm{C}$ until analysis. Additionally, at the same time points, an oral fluid sample (obtained by spitting in a polypropylene tube), a urine sample, and a sweat sample (by wiping a $5 \mathrm{~cm} \times 5 \mathrm{~cm}$ cotton-based fleeceSecuretec, Germany-moistened with $0.5 \mathrm{ml}$ of $70 \%$ of isopropanol over the forehead) were collected. Oral fluid, urine and sweat samples were frozen immediately.

\subsection{Study 2}

A total of 19 subjects, 14 male and 5 female, participated in a study on the effects of ecstasy during an evening on which they already intended to use MDMA. Subjects bought ecstasy for their own purpose (and mailed an extra tablet to the laboratory for substance analysis), using MDMA in a self-determined dosage. During the night of a party two rides in a driving simulator were made, one approximately $1 \mathrm{~h}$ after ingestion of MDMA, and one after the party when subjects normally would go home or to an after-party. Subjects were asked to take no more than one tablet before the first test ride. Between the first and second ride, subjects were allowed to take any psychoactive substance in any combination and dosage they would normally use. On a separate evening a non-drugs control test ride was completed at the same hour as the first MDMA ride, and on that day no drugs were allowed. The experimental design was approved by the Ethical Committee of the Department of Psychology of the University of Groningen. Questionnaires on used drugs were administered and subjects were asked to supply a urine sample to perform a general toxicological screening. The study protocol did not allow blood sampling because it was considered too invasive, but oral fluid samples were collected by spitting into polypropylene tubes.

\section{Analysis of biological samples}

\subsection{Plasma and urine}

All urine samples were screened with FPIA (Abbott Diagnostics Division, Belgium) for amphetamines, cocaine, cannabis, opiates, and benzodiazepines. Systematic toxicological analysis was performed with GC-MS-EI after solid phase extraction and separate elution of the acidic/neutral fraction and the basic fraction [6]. Specific screening and/or confirmation methods were applied to detect LSD and GHB in urine samples of subjects that reported the use of these drugs $[7,8]$. The amph and the designer amphetamines were extracted from urine and plasma using Bond Elut Certify columns (Varian, St. Katelijne-Waver, Belgium) according to the manufacturer's instructions [2]. They were derivatised with hepta-fluorobutyric anhydride (HFBA). Quantitative analyses were performed using the deuterated analogues of the analytes of interest and an Agilent 6890 gas chromatograph equipped with an autosampler (HP7673A) and interfaced with an Agilent 5973 mass selective detector (Agilent Technology, Woluwe, Belgium). Analytical conditions were optimised for the detection of amphetamine, methamphetamine, 3,4-methylenedioxy- $N$-amphetamine (MDA), MDMA, 3,4-methylenedioxy- $N$-ethyl-amphetamine (MDEA), $N$ methyl-1-(3,4-methylene-dioxy-phenyl)-2-butanamine (MBDB) and ephedrine. The MS was operated in SIM mode. At least three ions were monitored for the analytes and two ions for the internal standards. Limits of quantitation (LOQ) were $20 \mathrm{ng} / \mathrm{ml}$ for MDA and $10 \mathrm{ng} / \mathrm{ml}$ for the other amphetamines.

\subsection{Oral fluid and sweat}

After thorough centrifugation of the oral fluid samples, which were often viscous, $50 \mu \mathrm{l}$ of clear supernatant was 
transferred to an Eppendorf vial using a positive displacement pipette. The internal standards were added to obtain a final concentration of $40 \mathrm{ng} / \mathrm{ml}$ of amphetamine- $\mathrm{d}_{11}$, methamphetamine- $\mathrm{d}_{5}$, MDA- $\mathrm{d}_{5}$, MDMA- $\mathrm{d}_{5}$, MDEA- $\mathrm{d}_{6}$ and ephedrine- $\mathrm{d}_{5}$ (Promochem, Hertfordshire, UK).

The amphetamines were isolated from oral fluid using a simple methanol clean-up procedure and subsequently analysed using reversed phase HPLC-MS/MS. A Quattro Ultima (Micromass Ltd., UK) tandem mass spectrometer fitted with a z-spray ion source was used for the analyses. The instrument was operated in electrospray positive ionisation mode and was coupled to a Waters 2690 Alliance HPLC system. The mobile phase (A: $10 \mathrm{mM}$ ammonium acetate/B: $95 \%$ acetonitrile, $5 \% 10 \mathrm{mM}$ ammonium acetate) $(85 / 15)$ was delivered at a flow rate of $0.3 \mathrm{ml} / \mathrm{min}$. A Hypersil BDS $\mathrm{C}_{18}$ column $(100 \mathrm{~mm} \times 2.1 \mathrm{~mm}, 3.5 \mu \mathrm{m})$ was used. Quantification of the drugs and their deuterated analogues was performed using multiple reaction monitoring (MRM). The developed method has a chromatographic run time of $<5 \mathrm{~min}$. LOQ were $1-5 \mathrm{ng} / \mathrm{ml}$, estimated by analysis of $50 \mu \mathrm{l}$ of blank oral fluid samples spiked with a mixture of amphetamines, where the accuracy was $>80 \%$ and coefficient of variation $<20 \%$. Intra-day and inter-day coefficients of variation for a number of quality control samples varying from 10 to $1000 \mathrm{ng} / \mathrm{ml}$ were $<10 \%$.

Following the addition of $20 \mathrm{ng}$ of the relevant deuterated standards to the sweat wipes, the amphetamines were recovered from the cotton fleece with $5 \mathrm{ml}$ of methanol, which was concentrated to approximately $100 \mu \mathrm{l}$ using vacuum centrifugation (Jouan RC 10.22, Merck Eurolab, Leuven, Belgium). After addition of $100 \mu \mathrm{l}$ of LC mobile phase and after filtration through an HPLC-filter, $10 \mu \mathrm{l}$ of filtrate was injected into the LC-MS/MS, using identical chromatographic conditions as for oral fluid. LOQs were estimated by using moistened cotton fleeces wiped on the forehead of non-drug users and spiked with decreasing concentrations of amphetamines; for MDMA the LOQ was $5 \mathrm{ng} /$ wipe.

\section{Results and discussion}

\subsection{Study 1}

Ethanol Breath Analyser tests were all negative. All urine samples screened negative for cannabinoids, cocaine, opiates and benzodiazepines. MDMA levels in urine varied from $0.32 \mathrm{mg}$ MDMA/g creatinine to over $50 \mathrm{mg}$ MDMA/g creatinine, with an average value of $13 \pm 8 \mathrm{mg}$ MDMA/g creatinine at time $5 \mathrm{~h}$. At time $0 \mathrm{~h}$, all samples screened negative for the amphetamine group except one sample which contained $0.16 \mathrm{mg}$ MDMA/g creatinine.

The plasma concentrations within $5 \mathrm{~h}$ after administration of $75 \mathrm{mg}$ of MDMA varied from 21 to $295 \mathrm{ng} / \mathrm{ml}$ and reached a maximum at 2-4 h after administration with an average value of $178 \pm 52 \mathrm{ng} / \mathrm{ml}$ (Fig. 1). This concentration is in agreement with the results of a previously published controlled study [9] and is within the lower range of MDMA concentrations reported after blood analysis of impaired drivers (49-1510 $\mathrm{ng} / \mathrm{ml}$ ) [2]. MDA concentrations never exceeded $20 \mathrm{ng} / \mathrm{ml}$. The legal limit for driving under the influence of ecstasy in Belgium is $50 \mathrm{ng} \mathrm{MDMA} / \mathrm{ml}$ plasma.

Oral fluid concentrations of MDMA were generally higher than plasma concentrations, but the inter-subject variability was approximately three times higher for oral fluid, ranging from 50 to $6982 \mathrm{ng} / \mathrm{ml}$. This could partly be due to the nature of the samples which differed widely in viscosity and volume from one subject to another, and even within a particular subject. All of the samples would have been classified as "positive" taking the new cut-off values proposed by SAMHSA into account [10]. Peak oral fluid

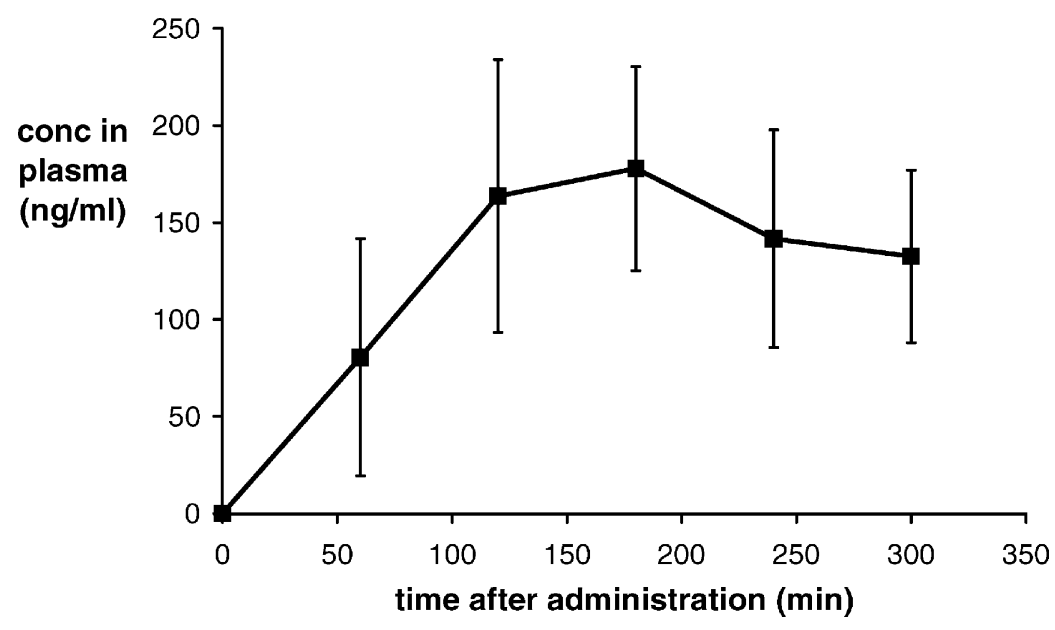

Fig. 1. Average plasma concentrations of MDMA as a function of time, after controlled administration of 75 mg of MDMA to 12 healthy volunteers. Error bars $=$ S.D. 


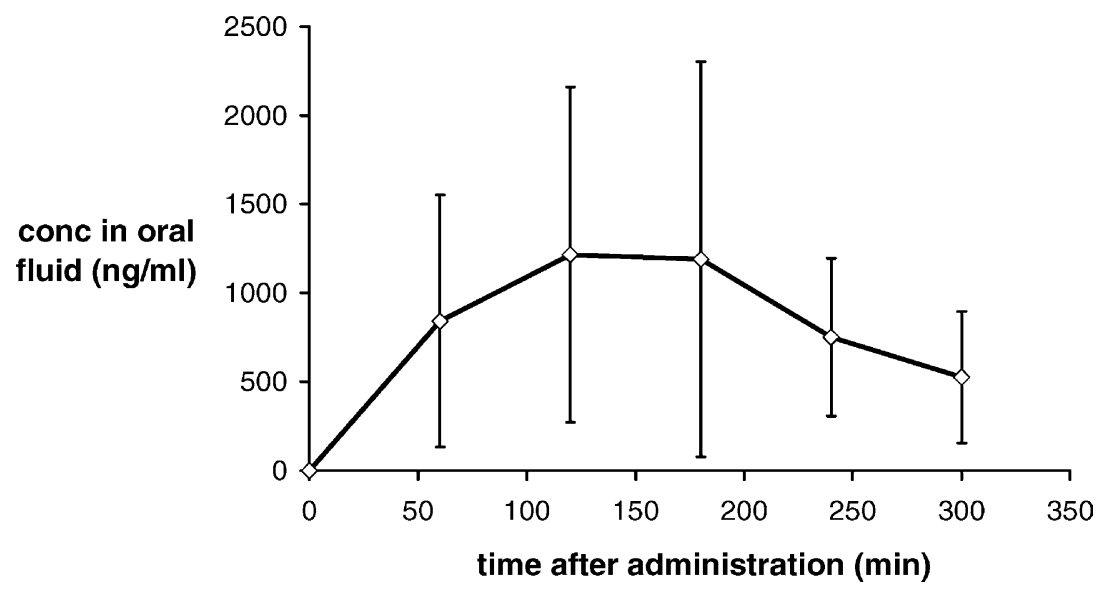

Fig. 2. Average oral fluid concentrations of MDMA as a function of time, after controlled administration of 75 mg of MDMA to 12 healthy volunteers. Error bars $=$ S.D.

concentrations of MDMA averaged $1215 \pm 944 \mathrm{ng} / \mathrm{ml}$ (Fig. 2). This value is lower than the one reported in a similar study [11] where average oral fluid concentrations peaked at $3375 \mathrm{ng} / \mathrm{ml}$. The dose of MDMA administered in that study was $100 \mathrm{mg}$, administered as two soft-gelatin capsules. On the other hand, the maximum concentration of MBDB in oral fluid after a controlled administration of $100 \mathrm{mg}$ to one subject was $1083 \mathrm{ng} / \mathrm{ml}$ [12]. Fig. 3 shows that the concentration-time course of the average levels of MDMA in plasma and in oral fluid was quite similar. However, in individual subjects, the correlation between concentrations of MDMA in plasma and in oral fluid was poor, resulting in variable saliva-to-plasma ratios $(\mathrm{S} / \mathrm{P})$ within a particular subject as a function of time. Moreover, inter-subject variability was high since average $\mathrm{S} / \mathrm{P}$ ratios per subject ranged from 0.8 to 22.4. Average $\mathrm{S} / \mathrm{P}$ ratios as a function of time are shown in Fig. 4. The maximum value is $12 \pm 6$, reached after $1 \mathrm{~h}$, then declining to $4 \pm 3$ at $4-5 \mathrm{~h}$ after intake. Since the dose of MDMA was dissolved in $25 \mathrm{ml}$ of orange syrup, contamination of the buccal cavity 60-120 min after administration seems highly unlikely. Saliva-to-plasma ratios $>1$ have been reported for MDMA in non-controlled studies of impaired drivers [13], and a median S/P ratio of $9 \pm 8$ was determined from 180 impaired drivers tested during the course of the European Commission project Rosita (Roadside Testing Assessment) in Belgium [14].

With the exception of two individual data points, MDMA levels obtained by extracting the sweat wipes with methanol remained $<50 \mathrm{ng} /$ wipe. A single administration of $75 \mathrm{mg}$ of MDMA resulted in average sweat concentrations not exceeding $25 \mathrm{ng}$ MDMA/wipe within the first $5 \mathrm{~h}$ (Fig. 5).

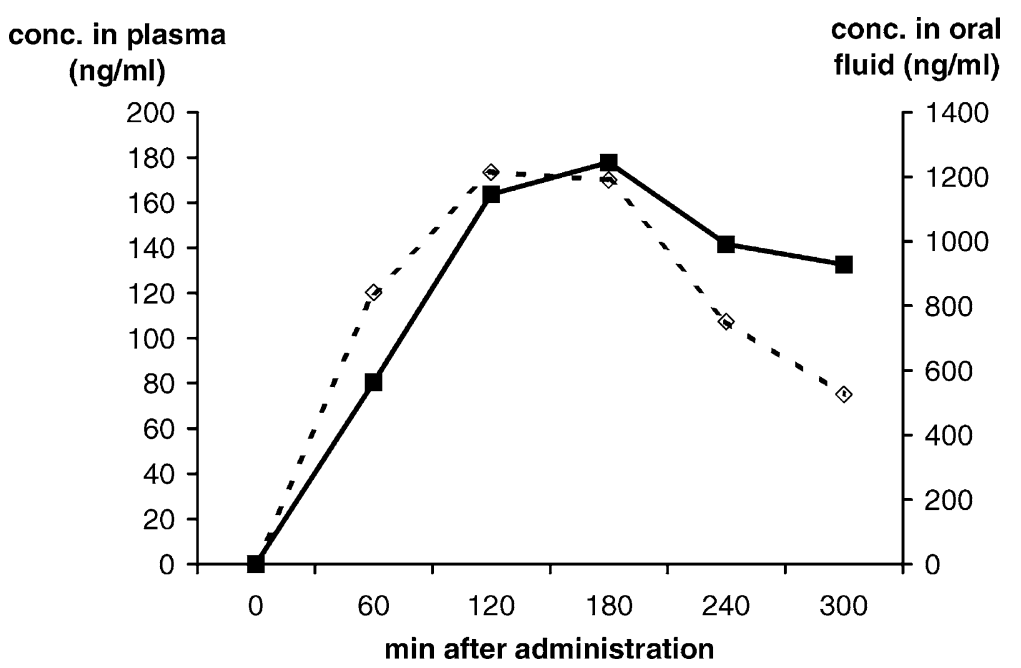

Fig. 3. Average plasma and oral fluid concentrations of MDMA as a function of time, after controlled administration of 75 mg of MDMA to 12 healthy volunteers: $(\boldsymbol{\square})$ plasma; $(\diamond$, dotted line) oral fluid. 


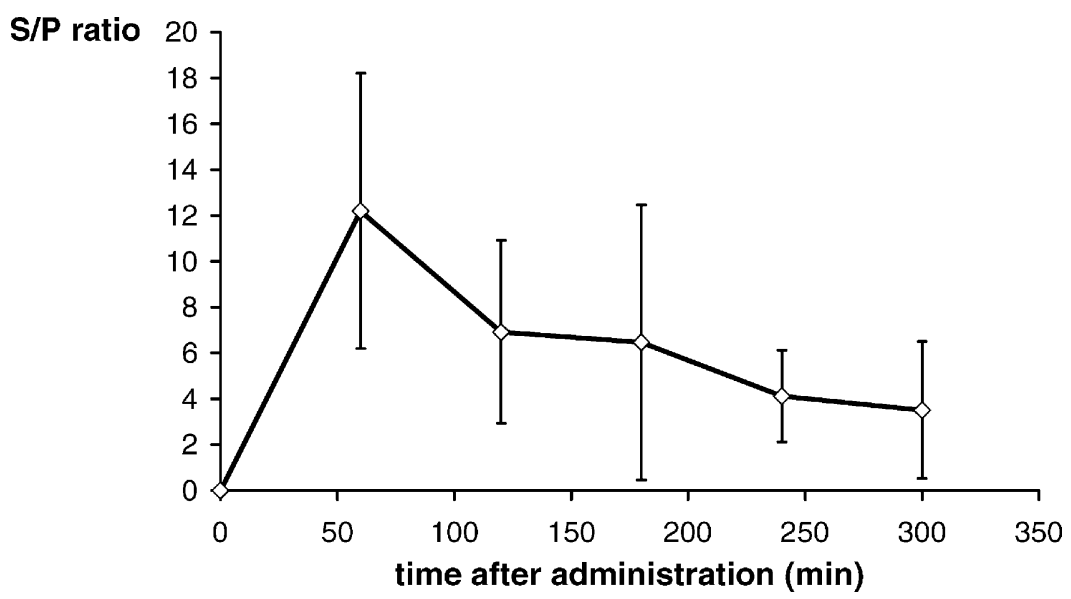

Fig. 4. Average saliva (oral fluid) to plasma concentration ratio (S/P) as a function of time, after controlled administration of 75 mg of MDMA to 12 healthy volunteers. Error bars = S.D.

In contrast to oral fluid, the results for sweat do not agree with reported MDMA levels obtained during the Rositaproject in Belgium [14]. Much higher concentrations of MDMA were reported ( 88 to $>20,000 \mathrm{ng} /$ wipe) in sweat samples obtained in a similar way (by wiping the forehead with the same type of cotton fleece) with a median value of $1813 \mathrm{ng} /$ wipe. Obviously, in that study, external contamination of the skin (e.g. by accidental touching of the forehead with contaminated hands), and especially, repeated dosing of MDMA during a certain interval before sampling, could not be excluded. In the current study, MDMA was administered under controlled conditions, with no possibility of external contamination. Fig. 5 shows that average concentrations are slowly increasing as a function of time, which could result in higher MDMA levels in sweat at a later time after administration. Therefore, more studies are needed on the toxicokinetics of MDMA in sweat wipes, extending the detection window and evaluating repeated dosing of MDMA. Kintz [12] reported sweat patch concentrations of MBDB in the low nanogram-range the first $4 \mathrm{~h}$ after administration, peaking at $44 \mathrm{ng} / \mathrm{patch}$ at $36 \mathrm{~h}$.

\subsection{Study 2}

\subsubsection{Analyses of amphetamine and designer amphetamines}

Subjects suffered from dry mouth and found it difficult to provide an oral fluid sample, especially in the multiple drug condition. Thus, the sample volume was extremely low in this study, requiring the use of a technique with a suitably low LOQ for the detection of the amphetamine group. Table 1 shows the concentrations of MDMA, MDEA and amph in oral fluid specimens obtained in the MDMA-only test condition and in the multiple-drug condition. Before the

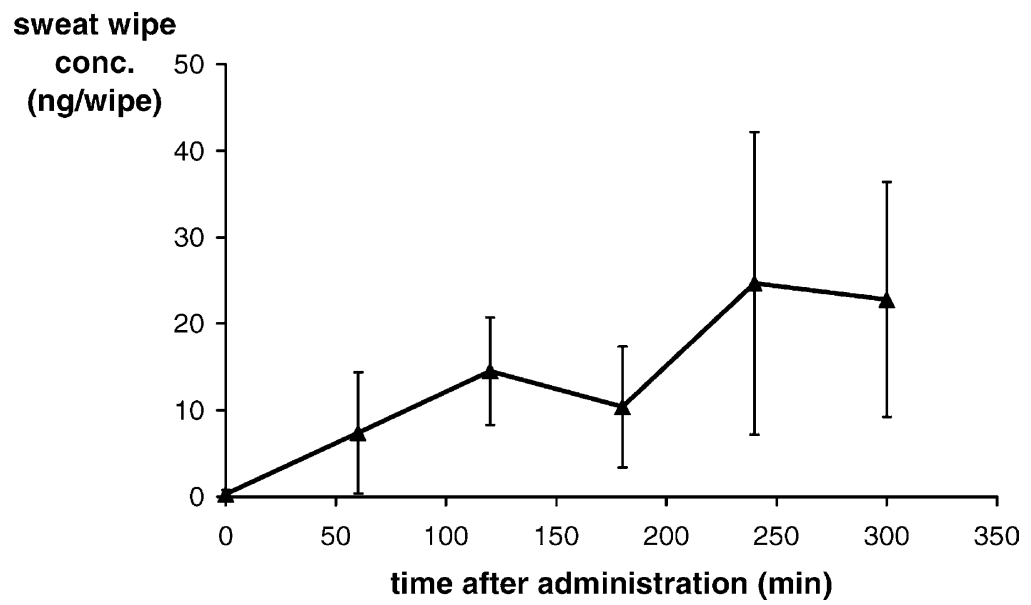

Fig. 5. Average sweat wipe concentrations of MDMA as a function of time, after controlled administration of 75 mg of MDMA to 12 healthy volunteers. Sweat samples were taken by wiping the forehead with a cotton fleece, moistened with $70 \%$ of isopropanol. Error bars $=$ S.D. 
Table 1

Oral fluid concentrations of amphetamines ( $\mathrm{ng} / \mathrm{ml}$ ) in Study 2 with an estimation of the amount of active substance taken before the test ride in the MDMA-only condition, and the number of extra tablets taken during the time interval between the two drug conditions

\begin{tabular}{|c|c|c|c|c|c|c|c|c|c|}
\hline \multirow[t]{2}{*}{ ID } & \multirow[t]{2}{*}{ "XTC" (mg) } & \multicolumn{3}{|c|}{ MDMA-only oral fluid } & \multirow[t]{2}{*}{ Extra tablets } & \multirow[t]{2}{*}{ Time interval } & \multicolumn{3}{|c|}{ Multiple drug oral fluid } \\
\hline & & MDMA & MDEA & amph & & & MDMA & MDEA & amph \\
\hline 1 & 37 & 2639 & & & 0 & 4.0 & 1354 & & \\
\hline 2 & 25 & 2003 & & & 0 & 4.0 & 1081 & & 382 \\
\hline 3 & - & 33 & & & 4.5 & 5.0 & 2027 & & 753 \\
\hline 4 & - & 248 & & & 1.5 & 5.0 & 1815 & & 257 \\
\hline 5 & 50 & 704 & & & 1.5 & 5.0 & 5519 & & \\
\hline 6 & 80 & 2466 & & & 1 & 4.0 & 7077 & & \\
\hline 7 & 58 & 1252 & & & 0 & 4.5 & 2190 & & \\
\hline 8 & 80 & 787 & & & 0.5 & 5.1 & 564 & 322 & \\
\hline 9 & 63 & & & 15 & 0.5 & 3.4 & 70 & 2479 & 407 \\
\hline 10 & 50 & 1181 & & & 3.5 & 5.2 & 1147 & & \\
\hline 11 & 32 & & 25 & & 0.5 & 5.1 & 38 & 1318 & \\
\hline 12 & 70 & 190 & & 60 & 0 & 3.4 & 986 & & 129 \\
\hline 13 & 25 & 352 & & & 2 & 6.2 & 1664 & & \\
\hline 14 & 54 & 2031 & & & 0.5 & 5.4 & 1454 & & 395 \\
\hline 15 & 58 & 3533 & & & 0 & 6.1 & 65 & & \\
\hline 16 & 44 & 228 & & & 0 & 4.0 & 1020 & & \\
\hline 17 & 63 & 55 & 2468 & & 0.5 & 22.1 & 19 & 1132 & \\
\hline 18 & 95 & 252 & & & 0.5 & 21.5 & 423 & 331 & \\
\hline 19 & 83 & 900 & & & 1.5 & 5.1 & 3778 & 3320 & \\
\hline
\end{tabular}

MDMA-only ride, most subjects reported taking one tablet according to the instructions. Two subjects did not send in the extra tablet for analysis. The average consumed dosage of stimulant of the other 17 subjects was $57 \pm 20 \mathrm{mg}$. In one case (subject 9), only amphetamine was taken; in two cases (subjects 11 and 17), the ingested dose consisted mainly of MDEA. Oral fluid samples in the MDMA-only condition were taken at an average time of $62 \pm 23$ min after intake of the ecstasy tablet. Concentrations of stimulant ranged from $15 \mathrm{ng} / \mathrm{ml}$ of amphetamine to $3533 \mathrm{ng} / \mathrm{ml}$ of MDMA (average $1121 \mathrm{ng} / \mathrm{ml}$ ). Table 1 also shows the time interval between oral fluid sampling in the MDMA-only test condition and in the multiple drug test condition and the self-reported number of "ecstasy" tablets that were taken between the two test rides. In six cases, no extra tablets were reported. In subjects 1,2 and 15, a decrease in oral fluid MDMA concentration was observed in the multiple-drug condition after, respectively, 4, 4 and $6.1 \mathrm{~h}$. In subjects 7, 12 and 16, however, an increase in the oral fluid MDMA concentration was observed although no additional MDMA intake was reported. This is either due to discrepancies in the self-reported drug use, intra-subject variability in the oral fluid concentrations of MDMA, as reported in Study 1, or incomplete absorption of MDMA in plasma and oral fluid at the time of the first test ride, which was 47, 47 and $40 \mathrm{~min}$ after intake of the tablet in subjects 7, 12 and 16, respectively. In the other 13 subjects, extra consumption of amphetamines in the time interval between the two drug conditions was reported, either additional MDMA, MDEA, or amphetamine, resulting in oral fluid concentrations exceeding the $50 \mathrm{ng} / \mathrm{ml}$ cut-off for at least one analyte. Concentrations ranged from 19 to $7077 \mathrm{ng} /$ ml MDMA, 322 to $3320 \mathrm{ng} / \mathrm{ml}$ MDEA and 129 to $753 \mathrm{ng} / \mathrm{ml}$ amphetamine.

Table 2 shows the amphetamine results in urine, expressed as $\mathrm{ng} / \mathrm{ml}$ to facilitate comparison with oral fluid quantitative data. There was a good qualitative correlation between the confirmatory results for amphetamines in urine and oral fluid. In only two cases, amphetamine was detected in urine but not in oral fluid. Table 2 also presents the GC-MS results of urine analyses in the non-drugs condition. In subjects 1,5 and 18, the presence of MDMA in urine was confirmed. The corresponding oral fluid concentrations for MDMA were 516, 20 and $47 \mathrm{ng} / \mathrm{ml}$, respectively. In subject 9 , amphetamine was detected in urine, with a corresponding oral fluid concentration of $97 \mathrm{ng} / \mathrm{ml}$. The $50 \mathrm{ng} / \mathrm{ml}$ cut-off level for oral fluid was thus exceeded in two subjects in the non-drug condition; one of them had reported the use of ecstasy the day before.

\subsubsection{Analyses of other drugs}

Urine analyses were performed to confirm the selfreported drug use of the subjects in the different study conditions and to detect non-reported additional psychoactive substances. Screening of urine samples in the multiple drug condition revealed the presence of amphetamine in 7 cases (6 reported), cannabis in 13 cases (16 reported), cocaine in 2 cases ( 2 reported), LSD in one case (1 reported), and psilocine in 2 cases (2 reported). GHB was never detected although reported twice, but the detection window of the analyte is $<10 \mathrm{~h}$, even in urine [15]. Cannabis was reported in $30 \%$ of the subjects in the non-drug condition. 
Table 2

Urine concentrations of amphetamines (ng/ml) in the different test conditions in Study 2: the non-drug control condition, the MDMA-only condition and the multiple drug condition

\begin{tabular}{|c|c|c|c|c|c|c|c|c|}
\hline \multirow[t]{2}{*}{ ID } & \multicolumn{2}{|c|}{ Non-drugs } & \multicolumn{3}{|c|}{ MDMA-only condition } & \multicolumn{3}{|c|}{ Multiple drug condition } \\
\hline & MDMA & amph & MDMA & MDEA & amph & MDMA & MDEA & amph \\
\hline 1 & 6689 & & $>20000$ & & & 9510 & & \\
\hline 2 & & & 5540 & & 1416 & 5480 & & 1542 \\
\hline 3 & & & 7530 & & & 7645 & & 2490 \\
\hline 4 & & & 1202 & & & $>20000$ & & 8780 \\
\hline 5 & 2007 & & 7900 & & & 3700 & & 1965 \\
\hline 6 & & & 1740 & & & $>20000$ & & \\
\hline 7 & & & 1389 & & & 11650 & & \\
\hline 8 & & & 17800 & & & 7000 & 4721 & \\
\hline 9 & & 1274 & & & 1192 & 266 & 8414 & 1928 \\
\hline 10 & & & $>20000$ & & & $>20000$ & & \\
\hline 11 & & & 517 & 3613 & & 1621 & $>20000$ & \\
\hline 12 & & & 1184 & & 284 & $>20000$ & & 4195 \\
\hline 13 & & & 2196 & & & $>20000$ & & \\
\hline 14 & & & $>20000$ & & & $>20000$ & & 2276 \\
\hline 15 & & & 13233 & & & $>20000$ & & \\
\hline 16 & & & 9993 & & & 6255 & & \\
\hline 17 & & & 320 & 10390 & & 591 & $>20000$ & \\
\hline 18 & 5405 & & $>20000$ & & & $>20000$ & 8836 & \\
\hline 19 & & & $>20000$ & & & $>20000$ & 16732 & \\
\hline
\end{tabular}

Urine analysis revealed the presence of cannabinoids in $60 \%$ of the cases, but since carboxytetrahydrocannabinol can be detected in urine for several weeks in regular users, there was no proof of recent use in the extra $30 \%$.

\section{Conclusions}

Since the number of experimental studies with MDMA is limited, the interpretation of MDMA concentrations in different matrices after a controlled administration of the drug is of considerable interest to the forensic toxicologist working in the field of drugs and driving and workplace drug testing. The results of Study 1 only represent a situation of recent abuse, showing toxicological data up to $5 \mathrm{~h}$ after administration. The average MDMA levels in plasma and oral fluid followed a similar time-course, but in individual subjects the intra- and inter-subject variability was much higher for oral fluid. Therefore, the interpretation of MDMA concentrations in oral fluid is extremely difficult without an additional quantitative confirmation of the corresponding blood sample. When a screening cut-off of $50 \mathrm{ng} / \mathrm{ml}$ of MDMA is applied, oral fluid offers a non-invasive alternative to urine testing with sufficiently high concentrations of MDMA detectable for at least $5 \mathrm{~h}$ after administration of a single dose of $75 \mathrm{mg}$ of MDMA. This is in contrast to the results for sweat; very low concentrations of MDMA were detected in the collected forehead wipes in the first $5 \mathrm{~h}$ after intake. In this study, external contamination and repeated dosage were completely ruled out.
In Study 2, test conditions were far less controlled, but much more representative of real-life situations of ecstasy abuse. Unfortunately, the interpretation of the results was rather difficult because blood analysis could not be performed in this study. The mean MDMA concentration observed at approximately one hour after intake of a "street" tablet of ecstasy (average content 56 mg MDMA) in a non-controlled experimental study design, was in the same range as oral fluid concentrations obtained after a controlled administration of $75 \mathrm{mg}$ of MDMA. However, as was the case in a controlled study design, the inter-subject variability was high. Oral fluid concentrations of amphetamines in a test situation of multiple drug use significantly exceeded the SAMHSA cut-off levels for amphetamines in oral fluid.

\section{References}

[1] F. Schifano, Dangerous driving and MDMA (ecstasy) abuse, J. Serotonin Res. 1 (1995) 53-57.

[2] N. Samyn, B. Viaene, B. Laeremans, G. De Boeck, V. Maes, First experience with the enforcement of the new per se DUID legislation in Belgium, in: I. Rasanen (Ed.), Proceedings of the 38th TIAFT Conference, Helsinki, Finland, 13-17 August 2000, pp. 106-116.

[3] C. Lamers, J.G. Ramaekers, N.D. Muntjewerff, K. Sikkema, N.L. Read, N. Samyn, K.A. Brookhuis, W.J. Riedel, Dissociable effects of a single dose of MDMA on psychomotor skills and attentional performance, Neuropsychopharmacology, 2002, in press. 
[4] D. De Waard, K.A. Brookhuis, L.M.C. Pernot, A driving simulator study on the effects of MDMA (ecstasy) on driving performance and traffic safety, in: Proceedings of the 15th ICADTS Conference, Stockholm, Sweden, 22-26 May 2000, p. 611.

[5] K.A. Brookhuis, D. De Waard, L.M.C. Pernot, A driving simulator study on driving performance and traffic safety after multiple drug use, consisting of MDMA (ecstasy) and various other psychoactive compounds, in: Proceedings of the 15th ICADTS Conference, Stockholm, Sweden, 22-26 May 2000, p. 602.

[6] J.P. Franke, R.A. de Zeeuw, Solid-phase extraction procedures in systematic toxicological analysis, J. Chromatogr. B 713 (1998) 51-59.

[7] A.G. Verstraete, S. Steyaert, Evaluation of the diagnostic performance of the Boehringer Mannheim CEDIA ${ }^{\circledR}$ LSD assay, J. Anal. Toxicol. 22 (1998) 601-604.

[8] F.J. Couper, B.K. Logan, Determination of $\lambda$-hydroxybutyrate (GHB) in biological specimens by gas chromatographymass spectrometry, J. Anal. Toxicol. 24 (2000) 1-7.

[9] M. Mas, M. Farré, R. de la Torre, P.N. Roset, J. Ortuno, J. Segura, J. Cami, Cardiovascular and neuroendocrine effects and pharmacokinetics of 3,4-methylene-dioxymethamphetamine in humans, J. Pharmacol. Exp. Ther. 290 (1999) 136-145.
[10] Substance Abuse and Mental Health Administration, Mandatory guidelines for federal workplace drug testing programs 2000. Available from www.health.org/workplace/ manguidelines/draft3.htm.

[11] M. Navarro, S. Pichini, M. Farré, J. Ortuno, P.N. Roset, J. Segura, R. de la Torre, Usefulness of saliva for measurement of 3,4-methylenedioxymethamphetamine and its metabolites: correlation with plasma drug concentrations and effect of salivary pH, Clin. Chem. 47 (2001) 1788-1795.

[12] P. Kintz, Excretion of MBDB and BDB in urine, saliva and sweat following single oral administration, J. Anal. Toxicol. 21 (1997) 570-575.

[13] N. Samyn, C. van Haeren, On-site testing of saliva and sweat with Drugwipe ${ }^{\circledR}$ and determination of concentrations of drugs of abuse in saliva plasma and urine of suspected users, Int. J. Legal Med. 113 (2000) 150-154.

[14] N. Samyn, B. Viaene, B. Laeremans, G. De Boeck: Evaluation of different roadside drug testing equipment, Contribution of Belgium, Deliverable D4 ROSITA Contract DG VII RO 98-SC.3032, 2000 (available from www.rosita.org).

[15] P.V. Kavanagh, P. Kenny, J. Feely, The urinary excretion of gamma-hydroxybutyric acid in man, J. Pharm. Pharmacol. 53 (2001) 399-402. 